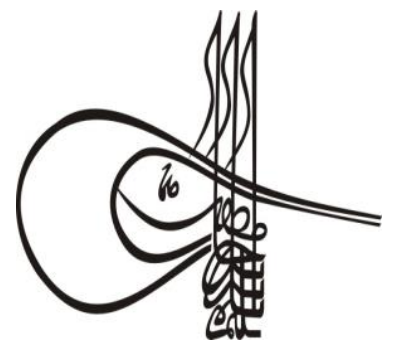

Received/Geliş: 03.11.2019
Turkish Studies

Volume 14 Issue 7, 2019, p. 3699-3711

DOI: 10.29228/TurkishStudies. 39580

ISSN: 1308-2140

Skopje/MACEDONIA-Ankara/TURKEY

Research Article / Araşttrma Makalesi

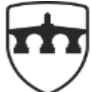

INTERNATIONAL BALKAN UNIVERSITY

EXCELLENCE FOR THE FUTURE IBU.EDU.MK

Article Info/Makale Bilgisi

Gor Report Dates/Rapor Tarihleri: Referee 1 (13.11.2019)-Referee 2 (21.11.2019)

This article was checked by iThenticate.

\title{
TÜRK-İSLAM MİMARİSİNDE YAZI VE SÜSLEME ÖZELLİKLERİ ANADOLU SELÇUKLU DÖNEMI (USTA ŞAGİRD KÜMBETİ ÖRNEĞİ)
}

\author{
Özgür ÇETINTAŞ*
}

\begin{abstract}
öz
Geleneksel sanatlarımızın merkezi konumunda olan Türk hat sanat1, 14. Yüzyıldan günümüze kadar eğitim, öğretim, icazet, meşk gibi tüm geleneklerini koruyarak gelmiştir. Sanat da tıpkı insanlar gibi etkileşim halinde bulunan bir olgudur. Sanat tarihi sürecinde geleneksel sanatlarımız da gerek doğu, gerekse batının sanat ve estetik anlayışından etkilenmiştir. Bu etkileşim neticesinde 19. Yüzyılda tezhip sanatımızda barok ve rokoko üslubu kendini göstermiştir. Geleneksel Türk ebru sanatında dalgalı ebrular (İspanyol şalı) da bu etkileşimin bir sonucu olarak gösterilebilir. Geleneksel sanatlarımızda bu etkileşimin görülmediği iki alandan biri hüsn-i hat sanatı iken diğeri de minyatür sanatıdır. Minyatür sanatında İran tarzı kendini gösteren başarılı bir örnek olmasına rağmen Türk nakkaşların bu tarzı uyguladıklarına dair elimizde örnek yoktur. Türk hat sanatının kendine muadil bir başka yazı sanatı olmaması da onu bu etkileşimin dışında tutmuştur. Elimizdeki kaynakların neredeyse tamamı hat sanatı tarihini İslam'ın gelișiyle başlatıp, Arap, Emevi, Abbasi ve Osmanlı İmparatorluğu devirleriyle günümüze kadar tanımlarlar. Bu kaynaklarda ilk dönem Arap yazısı ile Osmanlı dönemi hat sanatı ekolü en çok öne çıkan başlıklardır. Birçok kaynakta Selçuklu dönemi yazı sanatı üstünkörü geçilmiştir. Yapılan bu tanımlamanın doğru olmakla birlikte eksik olduğu kanaati bu araştırmanın temel amacıdır. Sürdürülen çalışmalar göstermiştir ki Büyük Selçuklu ve devamında gelen Anadolu Selçukluları döneminde de hat sanatı karakter bakımından değişiklikler göstermiştir. Zirve dönemini 13. Yüzyılda yaşayan Anadolu Selçuklu medeniyeti sanatın birçok alanında olduğu gibi hüsn-i hat ve süsleme sanatlarında da başarılı bir Türk-İslam medeniyetidir. Özellikle anıtsal mimaride bitkisel, geometrik süsleme ile hat sanatının gelişim sürecini izlemek mümkündür. Bunun yanı sıra Anadolu Selçuklu dönemi çini sanatı da hat sanatının gelişimini
\end{abstract}


takip edebilmemiz açısından önemli örnekler vermektedir. Hazırlanan bu araştırma geleneksel sanatlarımızın merkez noktasını teşkil eden hüsn-i sanatının gelişim sürecinde çok temas edilmemiş bir dönem olan Anadolu Selçukluları dönemi yazı sanatını ve Selçuklu sülüsü ile aynı dönemin süsleme özelliklerini tanıtmak bakımından önemlidir ve bu bağlamda literature katkı sunmak amacını taşımaktadır. Bu araştırmada kullanılan 3 numaralı resimdeki görseller 2017 yılında hazırlanan doktora tezinden alınmıştır.

Anahtar Kelimeler: Anadolu Selçuklu, İslam mimarisi, süsleme, hat sanati.

\title{
WRITING AND DECORATION PROPERTIES IN TURKISH- ISLAMIC ARCHITECTURE IN ANATOLIAN SELJUK PERIOD (USTA ŞAGIRD TOMB EXAMPLE)
}

\begin{abstract}
The Turkish calligraphy, which is the center of our traditional arts, has come from the $14^{\text {th }}$ century to the present day while preserving all its traditions such as education, teaching, ratification and model. Art, like human beings, is an interacting phenomenon. In the history of art, our traditional arts have been influenced by the art and aesthetic understanding of both the east and the west. As a result of this interaction, the baroque and rococo styles were revealed in our illumination art in the 19th century. In traditional Turkish marbling paper, wavy marbling (Spanish shawl) can also be shown as a result of this interaction. One of the two areas where this interaction is not seen in our traditional arts is Islamic calligraphy and the other one is miniature art. Although Iranian style is a successful example in miniature art, there is no example that Turkish miniaturists applied this style. The fact that the Turkish calligraphy does not have its equivalent has left it out of this interaction. Almost all of the sources we have starts the history of calligraphy with the advent of Islam and defines it with the Arab, Umayyad, Abbasid and Ottoman periods until today. In these sources, the first Arabic script and the Ottoman school of calligraphy are the most prominent titles. In many sources, the calligraphy of the Seljuk period was examined cursorily. The main reason of doing this research is the opinion that the definition is correct and incomplete. Ongoing studies have shown that calligraphy has changed in terms of calligraphy style during the period of the Great Seljuks and subsequent Anatolian Seljuks. Anatolian Seljuk civilization, which lived the peak period in the 13th century, is a successful Turkish-Islamic civilization in Islamic calligraphy and decorative arts as well as in many fields of art. It is possible to trace the development process of herbal, geometric decoration and calligraphy, especially, in monumental architecture. Besides, tile art of Anatolian Seljuk period gives important examples for us to follow the development of calligraphy.
\end{abstract}

This research is important in terms of introducing the calligraphy of Anatolian Seljuk period and ornamental features of Seljuk sulus which is not much studied during the development of Islamic calligraphy 
together with ornamentation of that period, which is the center point of our traditional arts, and in this context it is aimed to contribute to literature. The visuals in picture 3 are taken from the $\mathrm{PhD}$ thesis prepared in 2017.

\section{STRUCTURED ABSTRACT}

The Turkish calligraphy, which is the center of our traditional arts, has come from the $14^{\text {th }}$ century to the present day while preserving all its traditions such as education, teaching, ratification and model. Art, like human beings, is an interacting phenomenon. In the history of art, our traditional arts have been influenced by the art and aesthetic understanding of both the east and the west. . Almost all of the sources we have starts the history of calligraphy with the advent of Islam and defines it with the Arab, Umayyad, Abbasid and Ottoman periods until today. In these sources, the first Arabic script and the Ottoman school of calligraphy are the most prominent titles. In many sources, the calligraphy of the Seljuk period was examined cursorily. One of the most reliable sources of calligraphy in modern Turkish was written by Mahmud Bedreddin Yazir (d. 1952), known as "Kalem Güzeli", and he takes this name from his work "Medeniyet Âleminde Yazı ve İslam Medeniyetinde Kalem Güzeli". In this book, basic information about subjects such as calligraphy, the origin of Arabic script and tools, paper and ink preparation used in calligraphy are explained in detail. In the work, whereas chronological information about the history of calligraphy is not given; general information about calligraphy types beginning from the birth of calligraphy is given. The main reason of doing this research is the opinion that the definition is correct and incomplete. Ongoing studies have shown that calligraphy has changed in terms of calligraphy style during the period of the Great Seljuks and subsequent Anatolian Seljuks. Anatolian Seljuk civilization, which lived the peak period in the 13th century, is a successful Turkish-Islamic civilization in Islamic calligraphy and decorative arts as well as in many fields of art. It is possible to trace the development process of herbal, geometric decoration and calligraphy, especially, in monumental architecture. The existence of a known calligrapher in the period of Ghaznavids, Great Seljuks and Anatolian Seljuks is not mentioned by written sources. This situation requires studying other artworks and monumental architectures in order to follow the development of calligraphy during those periods. It is a pity not to be able to follow the succession of Islamic calligraphy as the calligrapher does not have his signature in examples of art branches such as tile, ceramics and hand-drawn besides the monumental architecture. However, the wooden handrails of the mosque pulleys and the wings of the pulpit doors can sometimes show the names of wood masters. The names of the carpenters can sometimes be seen on the wooden balustrades of the mosque minbar and on its edgings. But, it is still a matter of debate that how much these masters are familiar with calligraphy. In the aforementioned periods, the most commonly used type of calligraphy in monumental architecture is the Cufic line. The Cufic line continued to be used in architecture during the Great Seljuk and Anatolian Seljuk periods. However, the softening of the calligraphy, especially in the Abbasid period and the beginning of its application in more rounded lines, enabled the raise of the sulus calligraphy of the 
Anatolian Seljuks which replaced cufic called by applying it in monumental architecture frequently. Especially, from the 13th century onwards, all the calligraphies on domes, belts, mihrabs, pediments, and inscriptions of mosques were written in Seljuk sulus, and since the Ottoman period, this calligraphy formed the school of Turkish calligraphy by indicating its anatomical difference. Especially Alaaddin Mosque, with its stonework, calligraphy, tiles and all other structural and ornamental elements, reflects the grandeur of the Anatolian Seljuks in the best way. On the other hand, there are masterpieces bearing the Seljuk signature in almost every region of Anatolia. Ahlat, a district of Bitlis, is one of the places where these works can be seen mostly. This region is known for its more than 8000 gravestones and it is a region that houses many Seljuk cemeteries and dozens of tombs which are brought to light every day with the works carried out. Tomb of Master Şagird, also known as Ulu Kümbet, is a structure that stands out with decoration and is located in the south of the square cemetery. It was built on square-shaped ashlar of Ahlat. Like many other Seljuk domes, the dome consists of a cone that covers the cylindrical body and is two storey. The square funeral part is knitted with cut stone and covered with a cross vault. Three lattice windows brighten it and the area where the sarcophagus is located is now surrounded by curb stones. The exterior walls of the dome are very spectacular with its decoration and calligraphy. The corners of the square-shaped base are beveled into a polygon with 12 edges and bear the cylindrical body. Above the geometric horizontal belt at the top of these panels is the Ayatul Kursi line embroidered with Seljuk sulus. The inscription was embossed on white limestone. Basmala has a geometric interlacing motif and the calligraphy is simple in terms of movement and decoration, but it is quite dense in terms of sequence.

Decoration and calligraphy have been used in many fields for centuries. The ornamentation, which started with cave paintings, developed over time like cuneiform scripted on clay tablets and reached today in different ways. The separation of decoration and calligraphy into many different types is a contribution to art and civilization. In addition to providing a little information about the development process of the Islamic Calligraphy and Turkish-Islamic decorative arts in particular, this research aims to contribute to the field of Turkish-Islamic arts by addressing the Master Shagird Dome in Ahlat as an example of ornamentation in monumental and religious architecture of Islamic art. Compared to similar examples of Anatolian Seljuks, which have survived to the present with the least deterioration, the Master Shagird Cupola sheds light on the 13th century vault architecture and ornamental arts with its rich floral and geometric ornaments as well as the generous calligraphy of Seljuk sulus.

Keywords: Anatolian Seljuk, Islamic architecture, ornament, Islamic calligraphy.

\section{Giriş}

Geleneksel sanatlarımızın merkezi konumunda olan Türk hat sanat1, 14. Yüzyıldan günümüze kadar eğitim, öğretim, icazet, meşk gibi tüm geleneklerini koruyarak gelmiştir. Sanat da tıpk1 insanlar gibi etkileşim halinde bulunan bir olgudur. Sanat tarihi sürecinde geleneksel sanatlarımız da gerek doğu, gerekse batının sanat ve estetik anlayışından etkilenmiştir. Elimizdeki 
kaynakların neredeyse tamamı hat sanatı tarihini İslam'ın gelişiyle başlatıp, Arap, Emevi, Abbasi ve Osmanlı İmparatorluğu devirleriyle günümüze kadar tanımlarlar. Bu kaynaklarda ilk dönem Arap yazısı ile Osmanlı dönemi hat sanatı ekolü en çok öne çıkan başlıklardır. Birçok kaynakta Selçuklu dönemi yazı sanatı üstünkörü geçilmiştir. Hat sanatına dair günümüz Türkçesi ile yazılmış en güvenilir kaynakların başında Mahmud Bedreddin Yazır (öl. 1952) merhuma ait, kısaca "Kalem Güzeli" olarak bilinen ve tam adı "Medeniyet Âleminde Yazı ve İslam Medeniyetinde Kalem Güzeli” adlı eser gelmektedir. Bu eserde yazı hakkında genel bilgiler, Arap yazısının menşei, hat sanatı, hattatık, hat sanatında kullanılan araç-gereçler, kâğıt ve mürekkep hazırlama gibi çok temel konular detaylı bir şekilde açıklanmaktadır. Bu eserde hat sanatı tarihi ile ilgili kronolojik bir bilgi verilmezken; hat sanatının doğuşundan itibaren yazı çeşitleri ile ilgili genel bilgiler verilmiştir. Yapılan bu tanımlamanın doğru olmakla birlikte eksik olduğu kanaati bu araştırmanın temel amacıdır. Sürdürülen çalışmalar göstermiştir ki Büyük Selçuklu ve devamında gelen Anadolu Selçukluları döneminde de hat sanatı karakter bakımından değişiklikler göstermiştir. Zirve dönemini 13. Yüzyılda yaşayan Anadolu Selçuklu medeniyeti sanatın birçok alanında olduğu gibi hüsn-i hat ve süsleme sanatlarında da başarılı bir Türk-İslam medeniyetidir. Özellikle anıtsal mimaride bitkisel, geometrik süsleme ile hat sanatının gelişim sürecini izlemek mümkündür. Gazneliler, Büyük Selçuklu ve Anadolu Selçukluları devrinde tanınmış bir hattatın varlığı yazılı kaynaklarca belirtilmemektedir. Bu durum, hat sanatının bu devirlerdeki gelişim sürecini izleyebilmek için diğer sanat eserleri ve anıtsal mimari seçeneklerini kaçınılmaz kılmaktadır. Çini, seramik, kalemişi gibi sanat dallarında uygulanan hat sanatı örneklerinde, yazıyı yazan sanatkârın imzasının yer almaması hüsn-i hat silsilesinin takip edilememesi bakımından üzücüdür. Anıtsal mimaride ise benzer durum söz konusu olmakla birlikte cami minberlerinin ahşap korkuluklarında ve minber kapılarının kanatlarında zaman zaman dülgerlerin isimleri görülebilmektedir. Ancak bu noktada da dülgerlerin hat sanatına ne kadar vakıf oldukları tartışma konusudur. Şimdiye kadarki bahsedilen devirlerde, anıtsal mimaride en çok kullanılan yazı çeşidi kufi hattıdır. Büyük Selçuklu ve Anadolu Selçuklu devirlerinde de kufi hattı mimaride kullanılmaya devam edilmiştir. Ancak yazının özellikle Abbasiler devrinde yumuşaması ve daha yuvarlak hatlarla yazılmaya başlanması, Anadolu Selçukluları devrine gelindiğinde sülüs yazı karakterinin olgunlaşmasını sağlamış ve ortaya Selçuklu sülüsü adı verilen ve anıtsal mimaride sıklıkla kullanılarak kufi hattının yerini alan bir yazının çıkmasını sağlamıştır. Bilhassa 13. Yüzyıldan itibaren camilerin kubbe, kuşak, mihrap, alınlık, kitabe gibi yazılarının tamamı Selçuklu sülüsü ile yazılmış, Osmanlı döneminden itibaren bu yazı yine anatomik farklılıklar göstererek Türk hat sanatı ekolünü oluşturmuştur. Anadolu Selçuklu dönemi mimarisinin en güzel güzel örnekleri başkent Konya'da görülür. Özellikle Alaaddin Camii, taş işçiliği, hat sanatı, çinileri ve diğer tüm yapı ve süsleme elemanlarıyla Anadolu Selçuklularının ihtişamını en güzel biçimde yansıtan örnektir. Buna karşılık Anadolu'nun hemen her bölgesinde Selçuklu imzasını taşıyan şaheserler yer almaktadır. Bu eserlerin en yoğun olarak görülebileceği yerlerin başında Bitlis'in Ahlat ilçesi yer almaktadır. Bu bölge, 8000'den fazla mezar taşıyla tanınan ve sürdürülen çalışmalarla her gün yenileri gün yüzüne çıkarılan Selçuklu Mezarlığı ve onlarca kümbeti içinde barındıran bir bölgedir. Usta Şagird Kümbeti, diğer adıyla Ulu Kümbet tezyinatıyla öne çıkan bir yapıdır ve meydanlık mezarlığının güneyinde yer almaktadır. Kare planlı sekiz sıra kesme ahlat taşı üzerinde yükselmektedir. Diğer pek çok Selçuklu kümbeti gibi silindirik gövde üzerini kapatan bir külahtan ibaret olan kümbet iki katlıdır. Kare planlı cenazelik kısmı kesme taşla örülü ve çapraz tonozla örtülüdür. Üç mazgal penceresi bu mekânı aydınlatmaktadır ve sandukanın bulunduğu alan günümüzde bordür taşlarıyla belli edilmiştir. Kümbetin dış duvarları süsleme ve yazı bakımından çok gösterişlidir. Kare planlı kaidenin köşeleri pahlanarak 12 kenarlı bir poligon halini almıştır ve silindirik gövdeyi taşımaktadır. Bu panoların en üst noktasındaki geometrik yatay kuşağın üstünde Selçuklu sülüsü ile nakşedilmiş Ayet-el Kürsi satırı bulunmaktadır. Yazı, beyaz kireç taşı üzerine kabartma olarak işlenmiştir. Besmele üzerinde geometrik bir geçme motifi bulunmaktadır ve yazı hareke ve tezyini işaretler bakımından sade olmasına karşılık istif bakımından oldukça yoğundur. Süsleme ve yazı yüzyıllardır birçok alanda kullanılmaktadır. Mağara resimleri ile başlayan süsleme;

\section{Turkish Studies}

Volume 14 Issue 7, 2019 
kil tabletler üzerine yazılan çivi yazıları gibi zaman içerisinde gelişerek günümüze faklı yollarla ulaşmıştır. Süslemenin ve yazının birçok faklı çeşide ayrılması da bu uzun sürecin sanata ve medeniyete katkısıdır. Yapılan bu araştırma, özelde hüsn-i hat ve Türk-İslam süsleme sanatlarının gelişim süreci hakkında küçük bir bilgi içerdiği gibi İslam sanatında anıtsal ve dinî mimarîde süsleme hakkında örnek olarak Ahlat'daki Usta Şagird Kümbeti'ni ele alarak Türk-İslam sanatları alanına katkı sağlamayı amaçlamıştır. Anadolu Selçukluları döneminden günümüze kadar benzer örneklerine kıyasla en az bozulmayla ulaşan Usta Şagird Kümbeti, zengin bitkisel ve geometrik süslemelerinin yanı sıra az miktarda da olsa Selçuklu sülüsünün güzel bir örneği olan kuşak yazısıyla 13. Yüzyıl kümbet mimarisine ve süsleme sanatlarına 1şık tutmaktadır. Geometrik ve bitkisel süslemelerindeki çeşitlilik, mimari yüzeylerdeki planlama, farklı formlar arasında geçiş gibi önemli unsurları taşıdığı gibi, yazı kuşağında dikkat çeken istif ve harf anatomileriyle de Türk hat ekolünün önemli bir dönemini bizlere aktarmaktadır.

\section{Yazılı Kaynaklarda Hat Sanatı Tarihi}

Hat sanatına dair günümüz Türkçesi ile yazılmış en güvenilir kaynakların başında Mahmud Bedreddin Yazır (öl. 1952) merhuma ait, kısaca "Kalem Güzeli" olarak bilinen ve tam adı "Medeniyet Âleminde Yazı ve İslam Medeniyetinde Kalem Güzeli" adlı eser gelmektedir. Bu eserde yazı hakkında genel bilgiler, Arap yazısının menşei, hat sanatı, hattatık, hat sanatında kullanılan araç-gereçler, kâğıt ve mürekkep hazırlama gibi çok temel konular detaylı bir şekilde açıklanmaktadır. Bu eserde hat sanatı tarihi ile ilgili kronolojik bir bilgi verilmezken; hat sanatının doğuşundan itibaren yazı çeşitleri ile ilgili genel bilgiler verilmiştir. Makıli yazının ortaya çıkışı, ondan Kufî yazının türetilmesi ve yazının yayılma yolları ile yazı çeşitlerinin özelliklerine dair bilgiler içeren eser, hat sanatı tarihini Kufî yazıdan sülüs yazıya ve oradan da nesih yazı bahsine geçildiğinde Abbasi halifesi ve hattat İbn-i Mukle' ye bağlamaktadır. Ancak buradan sonra tarihi akış içerisinde hat sanatı sürecine pek yer verilmemiştir (Yazır, 1981: 75).

Hat sanatı ile ilgili bir diğer önemli kaynak olan "Devlet-i Aliyye'den Günümüze Hat Sanatı" adlı eser Dr. Süleyman Berk'e aittir ve bu eserde de Kalem Güzeli'ndeki benzer konular ele alınmaktadır. Eser içerisinde yapılan kronolojik sıralamada $\mathrm{Hz}$ Peygamber dönemi, Emeviler dönemi, Abbasiler dönemi yazı sanatından sonra Selçuklular döneminde celi yazı bahsine geçilmiş ve buradan sonra da Osmanlı yazı sanatına yer verilmiştir (Berk, 2013: 19). Bu alanda yazılmış önemli eserlerden biri de Muhiddin Serin'e aittir. "Hat San'atımız Tarihçesi-Malzeme ve AletlerMeşkler" başlığıyla kaleme alınan eser, yazı sanatının tarihini Asr-1 Saadet devrinden başlatarak Emeviler, Abbasiler, Memluklar devirlerinden sonra Gazneliler ve Selçuklulardan çok kısaca bahsederek Osmanlı İmparatorluğu devrine kadar takip etmiştir (Serin, 1982: 36).

\section{1. İlk (Asr-ı Saadet) Dönem Yazı Sanatı}

Bu dönemde Nebatî (Nebtî) yazı günlük yazışmalarda kullanılırken Ma'kılî yazı bizzat peygamberimiz tarafindan Kur'an ve dinî nassların yazılmasında tercih edilmiştir. Bu dönemin en önemli hattatı aynı zamanda vahiy katibi olan Hz. Ali'dir. Kendisinden başka Hz. Osman'ın da yazdığı Kur'an-1 Kerîm'deki kufi hattı Topkapı Sarayı Müzesi Kütüphanesi'nde sergilenmektedir ve görenleri hayrete düşürecek güzelliktedir (Serin, 1982: 36). 


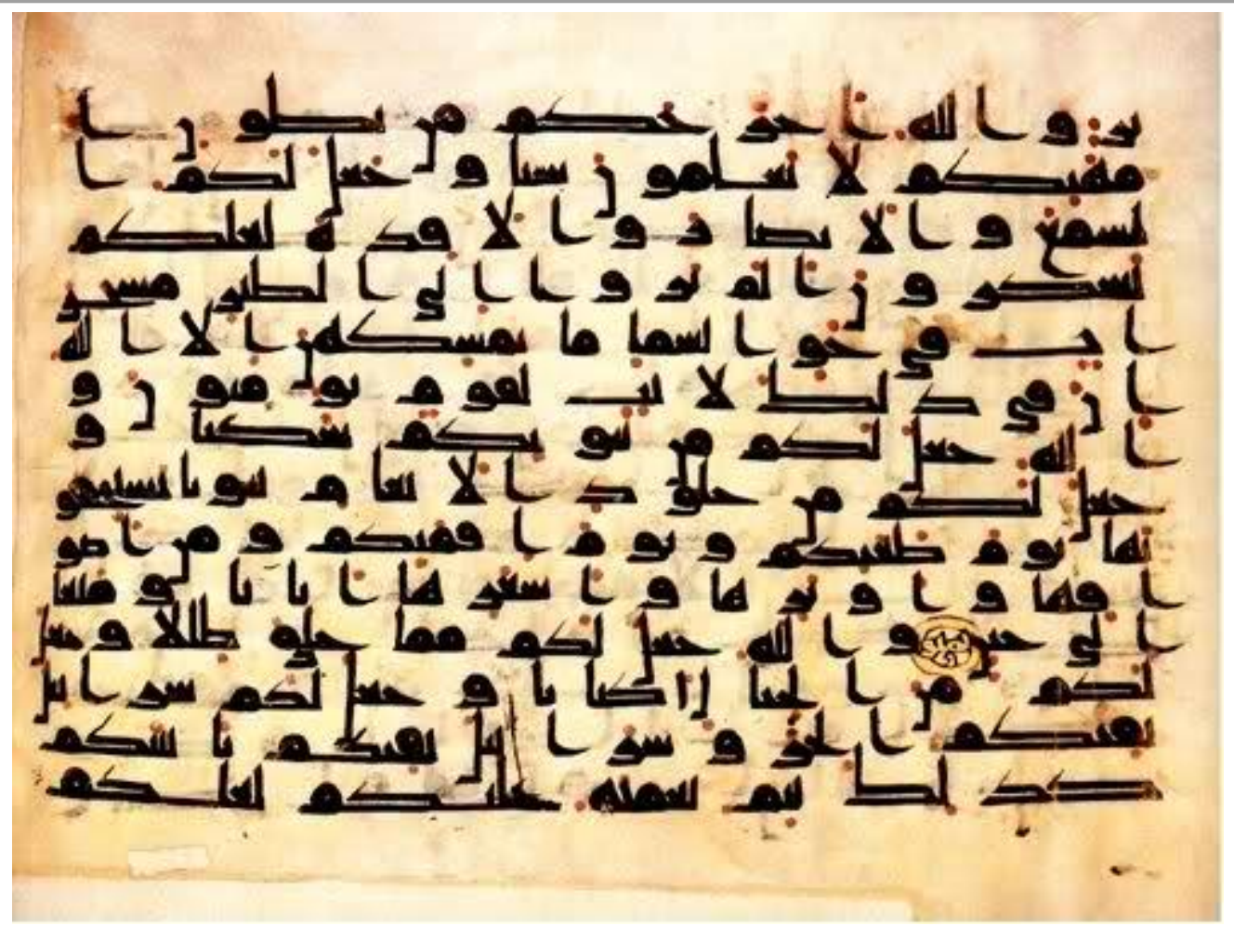

Resim 1: Hz. Osman'a atfedilen Kur'an-1 Kerim'den bir sayfa. https://www.tarihnotlari.com/hz-osmanin-oldurulmesi// (29.08. 2019).

\subsection{Emeviler Devrinde Yazi Sanatı}

Emeviler devri, yazı sanatı için çok büyük bir ilerleme kabul edilebilecek gelişmelerin yaşandığı bir dönemdir. Bu dönemde hat sanatının gelişimi daha çok yumuşak ve yuvarlak karakterli yazı üzerine olmuştur. Tarihte ilk defa hattat unvanı ile karşımıza çıkan şahıs Kutbetü'l Muharrir'dir. Emeviler'in sonu ile Abbasiler'in ilk yıllarında yaşayan Kutbetü'l Muharrir, daha önce kullanılan ve kalem ağzı genişliği belli olmayan celîl yazıya nisbeten kalem ağzı genişliği belli olan tumar yazıyı icat etmiştir ve bu yazı kendisinden sonra icat edilecek yazı çeşitleri için ölçü görevi üstlenmiştir (Berk, 2003: 71).

\subsection{Abbasiler Devrinde Yazı Sanatı}

Abbasiler devri, yazı sanatı için oldukça parlak bir dönemdir. Abbasilerin ilk devirlerinde Kutbetü'l Muharrir eserler vermiş ve kendisinden sonra gelen birçok hattat da yazı sanatını onun yolunda geliştirmeye devam etmiştir. Bu hattatlardan birisi İbn Mukle adıyla meşhur ve aynı zamanda vezir olan Ebû Ali Muhammed b. Ali'dir. Kendisini hat sanatı tarihinde bu kadar önemli noktaya taşıyan başarısı, harfleri belirli ölçülerle yazması olmuştur. Bu dönemde yazı, kufi etkisinden çıkıp aklâm-1 sitte'ye doğru evrilmiştir. Bu durum hat sanatının tutarlı biçimde öğretilebilmesi ve talim edilebilmesi bakımından oldukça önemlidir. İbn Mukle'den sonra İbn-i Bevvâb onun ekolünü devam ettirmiştir. Nesih hattın Kur'an nüshalarında yaygınlaşmasına yol açan, Abbasi döneminin ünlü hattatı İbn Bevvab'ın istinsah ettiği Kur'an nüshalarının tezhipleri üstat bir müzehhibin elinden çıkmıştır. Kur'an nüshaları da aherli kâğıt üzerine yazılmış ve yatay biçimde değil, dikeyde tasarlanmaya başlamıştır (Tanındı, 2012: 244). Kendisinden iki asır sonra, Ebu'l Mecd Cemaleddin Yakut b. Musta'sımî yazıya yeni bir nefes vermiş ve yazı sanatında çok önemli bir değişiklik olarak o zamana kadar düz kesilen kalem ağzını eğik keserek kalemin açısını artırmıştır. Hat sanatı tarihinde Yâkût adıyla meşhur olan hattat, özellikle muhakkak ve reyhanî yazılarda ortaya koyduğu estetik 
kurallarla Türk hat sanatı ekolünün doğuşuna kadar ideal örnek kabul edilen yazılara imza atmıştır (Berk, 2003: 72). Yakut'a kadar sülüsün tekamülü seyri devam etmiş ve bu zat onu çok ilerletmiştir (Ünver, 1953: 6).

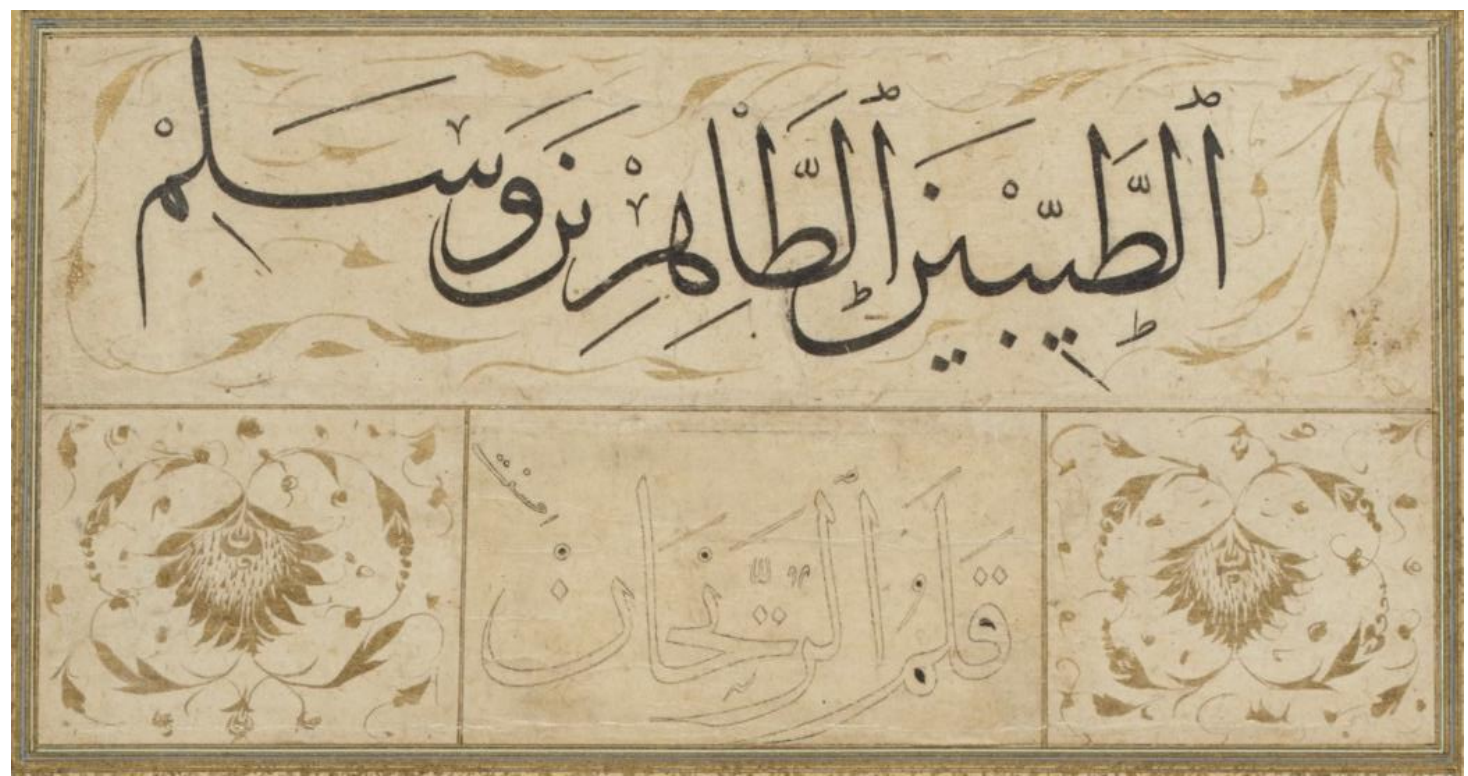

Resim 2: Yakut el-Musta'sımî'ye ait murakkadan reyhani yazı örneği. https://gallica.bnf.fr/ark:/12148/btv1b8406165m/f18.image (04. 08. 2019)

\subsection{Gazneli, Büyük Selçuklu ve Anadolu Selçuklular Devrinde Yazı}

Gazneliler, Büyük Selçuklu ve Anadolu Selçukluları devrinde tanınmış bir hattatın varlığı yazılı kaynaklarca belirtilmemektedir. Bu durum, hat sanatının bu devirlerdeki gelişim sürecini izleyebilmek için diğer sanat eserleri ve anıtsal mimari seçeneklerini kaçınılmaz kılmaktadır. Çini, seramik, kalemişi gibi sanat dallarında uygulanan hat sanatı örneklerinde, yazıyı yazan sanatkârın imzasının yer almaması hüsn-i hat silsilesinin takip edilememesi bakımından üzücüdür. Anıtsal mimaride ise benzer durum söz konusu olmakla birlikte cami minberlerinin ahşap korkuluklarında ve minber kapılarının kanatlarında zaman zaman dülgerlerin isimleri görülebilmektedir. Ancak bu noktada da dülgerlerin hat sanatına ne kadar vakıf oldukları tartışma konusudur. Çünkü Anadolu Selçuklularına ait birçok kitabe sıkışık şekilde ve hüsn-i hat sanatı bakımından düşük diyebileceğimiz kalitede yazılmıştır. Özellikle mimari yapılardaki kitabe yazılarının sanatsal değeri olduğunu söylemek zordur. Yapıyla ilgili temel bilgileri içermesi amacıyla yazılan bu kitabelerde hat sanatının yapısal özelliklerini ve karakter gelişimini incelemek mümkündür.

\section{Usta Şagird Kümbeti Yazı ve Süsleme Özellikleri}

Şimdiye kadarki bahsedilen devirlerde, anıtsal mimaride en çok kullanılan yazı çeşidi kufi hattıdır. Büyük Selçuklu ve Anadolu Selçuklu devirlerinde de kufi hattı mimaride kullanılmaya devam edilmiştir. Ancak yazının özellikle Abbasiler devrinde yumuşaması ve daha yuvarlak hatlarla yazılmaya başlanması, Anadolu Selçukluları devrine gelindiğinde sülüs yazı karakterinin olgunlaşmasını sağlamış ve ortaya Selçuklu sülüsü adı verilen ve anıtsal mimaride sıklıkla kullanılarak kufi hattının yerini alan bir yazının çıkmasını sağlamıştır. Bilhassa 13. Yüzyıldan itibaren camilerin kubbe, kuşak, mihrap, alınlık, kitabe gibi yazılarının tamamı Selçuklu sülüsü ile yazılmış, Osmanlı döneminden itibaren bu yazı yine anatomik farklılıklar göstererek Türk hat sanatı ekolünü oluşturmuştur. Taş bezemenin özellikle 13. Yüzyılda, çok zenginleşen Selçuk mimarisinde girift ve başarılı örnekler verdiğini görürüz. Genellikle 13. Yüzyılın ilk yarısından olan erken 
örnekler daha yassı kabartma, tekstil karakterinde bezeme ile dikkati çeker (Öney, 1992: 9). Anadolu Selçuklu dönemi mimarisinin en güzel güzel örnekleri başkent Konya'da görülür. Özellikle Alaaddin Camii, taş işçiliği, hat sanatı, çinileri ve diğer tüm yapı ve süsleme elemanlarıyla Anadolu Selçuklularının ihtişamını en güzel biçimde yansıtan örnektir.
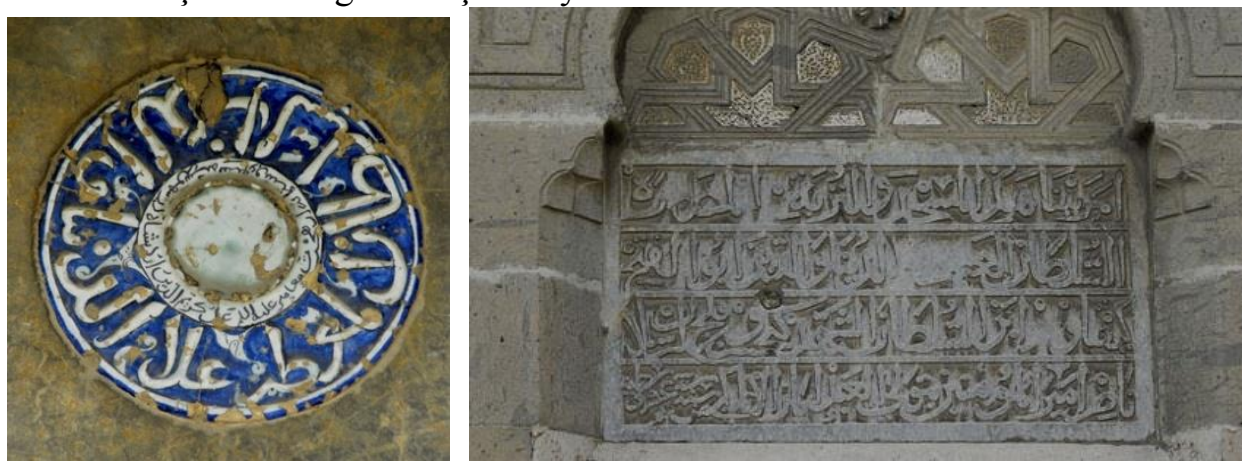

Resim 3: Konya Alaaddin Camii’nde çini ve kitabe yazıları.

Buna karşılık Anadolu'nun hemen her bölgesinde Selçuklu imzasını taşıan şaheserler yer almaktadır. Bu eserlerin en yoğun olarak görülebileceği yerlerin başında Bitlis'in Ahlat ilçesi yer almaktadır. Bu bölge, 8000'den fazla mezar taşıyla tanınan ve sürdürülen çalışmalarla her gün yenileri gün yüzüne çıkarılan Selçuklu Mezarlığı ve onlarca kümbeti içinde barındıran bir bölgedir. Vasıflarına göre çatma lahitliler, şahidesiz prizmatik sandukalar ve şahideli mezarlar olmak üzere üç ana grupta incelenen mezarlarının yanı sıra (Karamağaralı, 1993: 6); Kubbe’t-ül İslam adıyla da bilinen Ahlat, Selçuklular döneminin kadı, emir ve hatunlarının medfun bulunduğu ve Anadolu Selçukluları için çok büyük önem taşıyan bir yerleşimdir. Usta Şagird Kümbeti, diğer adıyla Ulu Kümbet tezyinatıyla öne çıkan bir yapıdır ve meydanlık mezarlı̆̆ının güneyinde yer almaktadır. Kare planlı sekiz sıra kesme ahlat taşı üzerinde yükselmektedir. Diğer pek çok Selçuklu kümbeti gibi silindirik gövde üzerini kapatan bir külahtan ibaret olan kümbet iki katlıdır. 


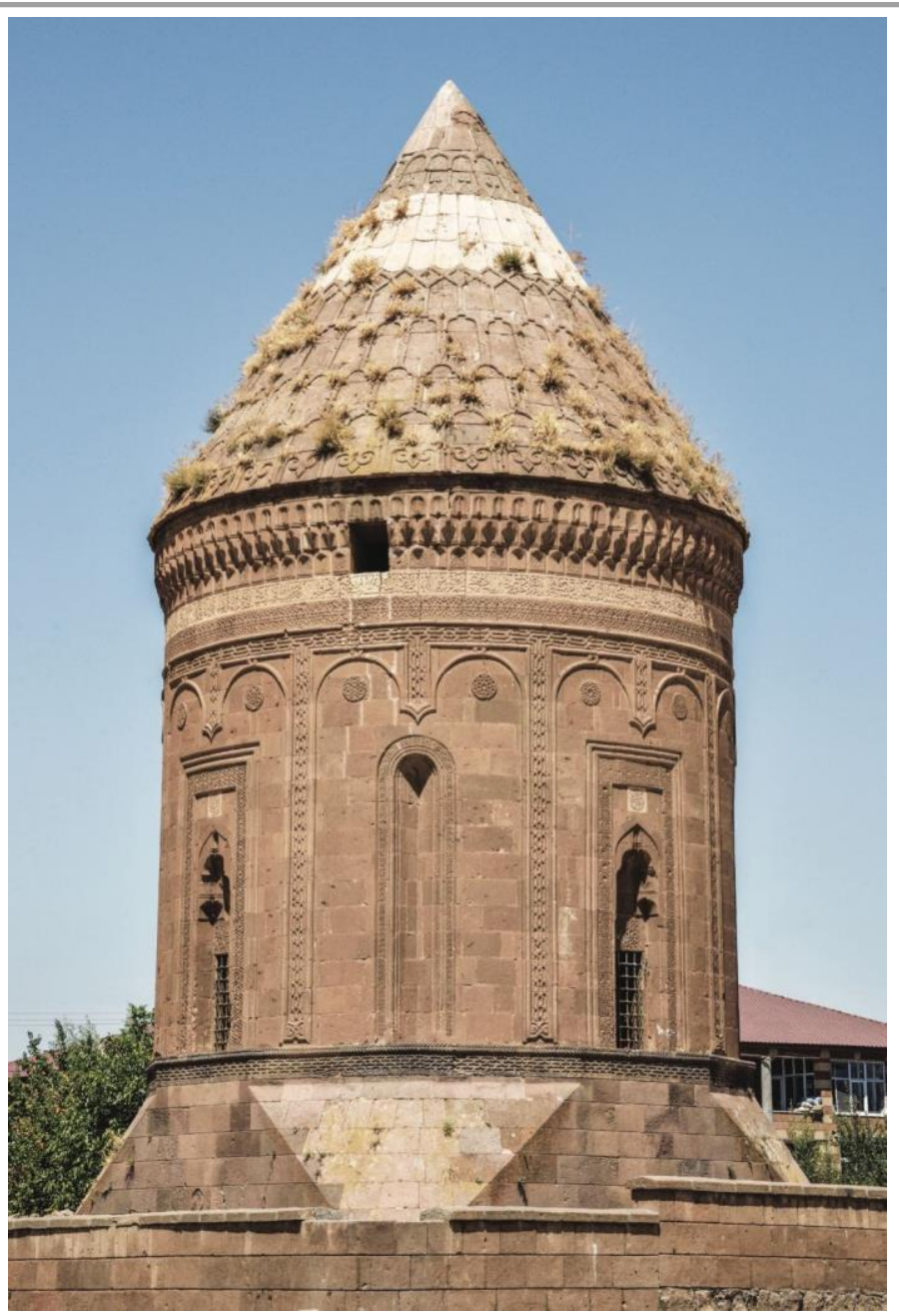

Resim 4: Ahlat Usta Şagird Kümbeti.

İç mekânı aydınlatan üç adet pencere silindirik gövde üzerindeki nişlerin içine yerleştirilmiştir. Güneydeki pencere aynı zamanda mihrap vazifesi de gördüğünden diğer ikisi kadar sade değildir. Üç sıra mukarnasla biten bir niş içinde yer almaktadır. Yapıdaki mazgal penceresi aydınlatma görevi taşımaz ancak mazgal penceresidir. Kare planlı cenazelik kısmı kesme taşla örülü ve çapraz tonozla örtülüdür. Üç mazgal penceresi bu mekânı aydınlatmaktadır ve sandukanın bulunduğu alan günümüzde bordür taşlarıyla belli edilmiştir. Kümbetin dış duvarları süsleme ve yazı bakımından çok gösterişlidir. Kare planlı kaidenin köşeleri pahlanarak 12 kenarlı bir poligon halini almıştır ve silindirik gövdeyi taşımaktadır. 


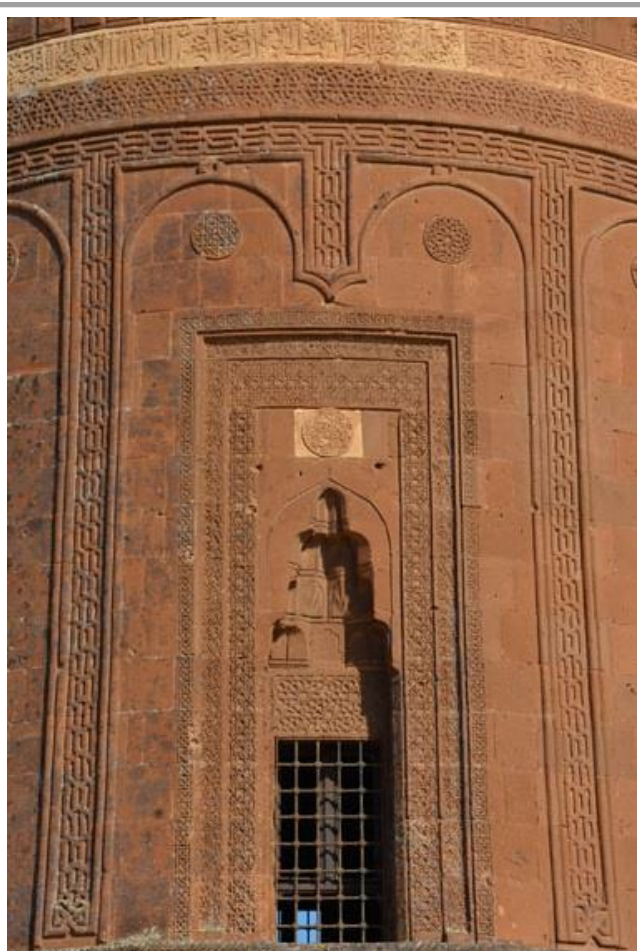

Resim 5: Ahlat Usta Şagird Kümbeti silmeleri, kitabe alınlığı ve yazı kuşağı.

Bu poligonal yapı, köşeli geçmeler ve çift halat örgülerle süslüdür. Daha önce belirtilen mazgal pencereleri, dıştan bakıldığında Bursa kemerli yüzeysel nişler içine alınmış ve kemerle pencereler arasındaki alınlık boşluklarına farklı desenlere sahip rozet motifleri işlenmiştir. Silindirik gövde, ince kaval silmelerle sekiz ayrı panoya bölünmüştür (Önkal, 2015: 193). Bu panoların en üst noktasındaki geometrik yatay kuşağın üstünde Selçuklu sülüsü ile nakşedilmiş Ayet-el Kürsi satırı bulunmaktadır. Yazı, beyaz kireç tașı üzerine kabartma olarak ișlenmiștir. Besmele üzerinde geometrik bir geçme motifi bulunmaktadır ve yazı hareke ve tezyini işaretler bakımından sade olmasına karşı1ık istif bakımından oldukça yoğundur.

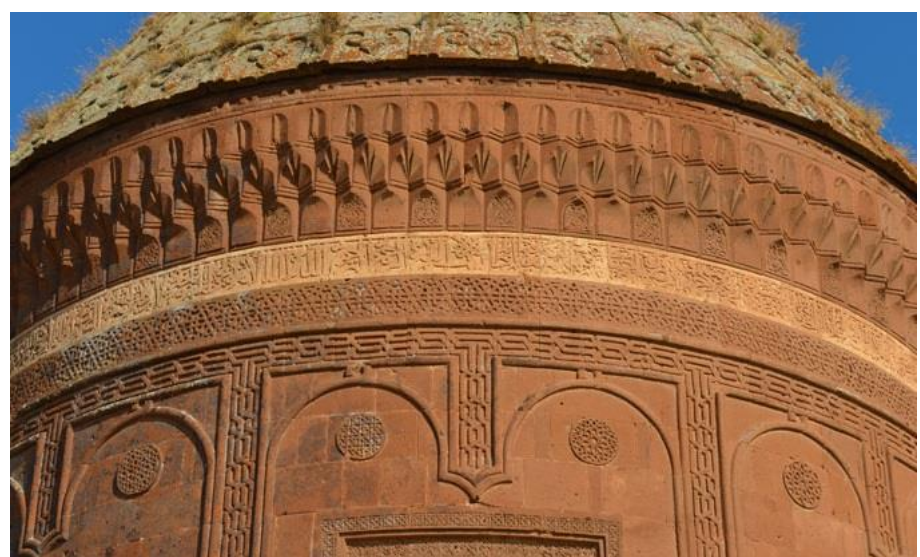

Resim 6: Ahlat Usta Şagird Kümbeti yazı kuşağı.

Dikdörtgen panoları çevreleyen silmeler tepe kısmında ikili kemerler oluşturmakta ve bu kemerlerin üst noktadaki boşluklarında geometrik motifli birer rozet görülmektedir. Kuzey tarafindaki panonun içinde bulunan giriş açıklı̆̆ 1 beş sıra mukarnasla sonlanan bir niş içindedir. Kitabe için ayrılan fakat içerisinde kitabe yerine yıldız geçme motiflerinin yer aldığı kitabe taşı bu 
mukarnas sırasının altında yer almaktadır. Bu niş, birbirini takip eden ve son derece girift şekilde süslenmiş iki silme ile dikdörtgen çerçeve içine alınmıştır. İçteki silmede beş köşeli küçük yıldızlar ve dıştaki silme kıvrık dal ve üç yapraklı palmet motifleri ile süslenmiştir.

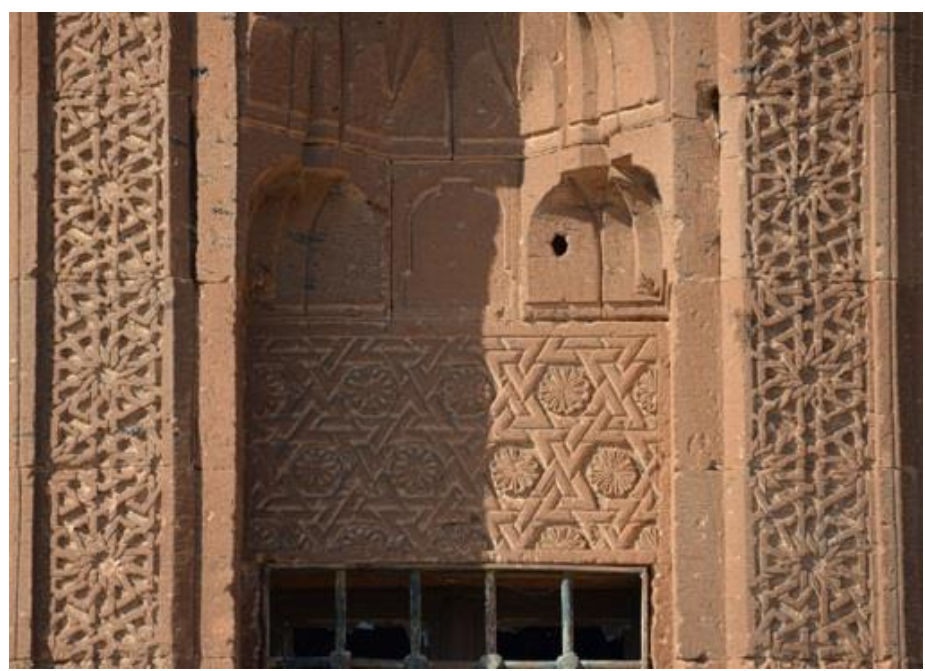

Resim 7: Ahlat Usta Şagird Kümbeti pencere alınlığı bordür süslemeleri.

\section{Sonuç}

Süsleme ve yazı yüzyıllardır birçok alanda kullanılmaktadır. Mağara resimleri ile başlayan süsleme; kil tabletler üzerine yazılan çivi yazıları gibi zaman içerisinde gelişerek günümüze faklı yollarla ulaşmıştır. Süslemenin ve yazının birçok faklı çeşide ayrılması da bu uzun sürecin sanata ve medeniyete katkısıdır. Yapılan bu araştırma, özelde hüsn-i hat ve Türk-İslam süsleme sanatlarının gelişim süreci hakkında küçük bir bilgi içerdiği gibi İslam sanatında anıtsal ve dinî mimarîde süsleme hakkında örnek olarak Ahlat'daki Usta Şagird Kümbeti'ni ele alarak Türk-İslam sanatları alanına katkı sağlamayı amaçlamıştır. Anadolu Selçukluları döneminden günümüze kadar benzer örneklerine kıyasla en az bozulmayla ulaşan Usta Şagird Kümbeti, zengin bitkisel ve geometrik süslemelerinin yanı sıra az miktarda da olsa Selçuklu sülüsünün güzel bir örneği olan kuşak yazısıyla 13. Yüzyıl kümbet mimarisine ve süsleme sanatlarına 1şık tutmaktadır. Geometrik ve bitkisel süslemelerindeki çeşitlilik, mimari yüzeylerdeki planlama, farklı formlar arasında geçiş gibi önemli unsurları taşıdığı gibi, yazı kuşağında dikkat çeken istif ve harf anatomileriyle de Türk hat ekolünün önemli bir dönemini bizlere aktarmaktadır. Yapının kendisi ve çevresindeki diğer yapılar incelendiğinde Türk hat sanatı ekolünün Selçuklu dönemi hakkında önemli bilgiler edinilmektedir. $\mathrm{Bu}$ bilgiler ışığında hazırlanan bu çalışma umarız ki Türk-İslam mimarisinde yazı ve süsleme kullanımı alanlarında gelecekte yapılacak başka çalışmalara katkı sağlar.

\section{KAYNAKÇA}

Berk, S. (2003), "Hattat Mustafa Râkım Efendi”, Kaynak Yayınları, İstanbul.

Karamağaralı, B. (1993), “Türk Mimari Eserlerinde Ahlat Mezartaşları”, Elila Yayınları, Ankara.

Öney, G. (1992), “Anadolu Selçuklu Mimari Süslemesi ve El Sanatları”, Türkiye İş Bankası Kültür Yayınları, Ankara.

Önkal, H. (2015), “Anadolu Selçuklu Türbeleri”, Atatürk Kültür Merkezi Yayınları, Ankara.

Serin, M. (1982), "Hat San'atımız”, Kubbealtı Neşriyatı, İstanbul. 
Tanınd1, Z. (2012), Hat ve Tezhip Sanatı içinde “Başlangıcından Osmanlı'ya Tezhip Sanatı”, Kültür ve Turizm Bakanlığı Yayınları, Ankara.

Ünver, A. S. , “Türk Yazı Çeşitleri ve Faideli Ba’zı Bilgiler”, Yeni Laboratuvar Yayınları, İstanbul.

Yazır, M. B. (1981), “Medeniyet Aleminde Yazı ve İslam Medeniyetinde Kalem Güzeli”, Diyanet İşleri Başkanlığı Yayınları, Ankara.

https://gallica.bnf.fr/ark:/12148/btv1b8406165m/f18.image

https://www.tarihnotlari.com/hz-osmanin-oldurulmesi/ 